\title{
Towards Semi-Industrialized Economy in Tanzania: The Higher Learning Institutions-Industry Linkage
}

\author{
Yustin Bangi \\ Department of Management Sciences, Institute of Finance Management, Dar es Salaam, Tanzania \\ Email: ybangi67@gmail.com, yustin.bangi@ifm.ac.tz
}

How to cite this paper: Bangi, Y. (2020) Towards Semi-Industrialized Economy in Tanzania: The Higher Learning InstitutionsIndustry Linkage. Open Access Library Journal, 7: e7038.

https://doi.org/10.4236/oalib.1107038

Received: November 25, 2020

Accepted: December 28, 2020

Published: December 31, 2020

Copyright $\odot 2020$ by author(s) and Open Access Library Inc.

This work is licensed under the Creative Commons Attribution International License (CC BY 4.0).

http://creativecommons.org/licenses/by/4.0/ (c) (i) Open Access

\begin{abstract}
The linkage between academia and the industry is increasingly becoming an essential component of national economic development. Industries depend much on their workforce from Higher Learning Institutions (HLIs) for both innovation and technological development. On the other hand, strong linkage scales down unemployment risk. As a result, this study assessed the existing linkage between HLIs and industry and its contribution towards semi- industrialized economy. The study involved two Universities, three non-university institutions and five local industries in Dar es Salaam and Coastal regions. Data were collected through interviews and desktop survey from the selected institutions' databases. Five (5) research directors, ten (10) faculty deans from HLIs, and five officials (5) from five industries were purposively selected and interviewed. The collected data were then thematically analyzed. Findings from the study suggest that the linkage in terms of training output is moderate. Knowledge is mainly transferred from HLIs to industries through field placement and employment opportunities of the trained workforce. Likewise, research and consultancy services linkage are still very low compared to the training and consultancy functions. It is further revealed that low motivation to academicians, lack of trust among industry owners towards HLIs, and meager budgets for research and consultancies are some of the factors that hinder the desired linkage. Conclusively, there exists a weak linkage between HLIs and industries in Tanzania. It is, therefore, suggested that the government should be involved, and should legitimize the collaboration. The objective is to smoothen the road towards the industrial economy. Engagement of the parties at all levels is required by raising awareness and participation.
\end{abstract}

\section{Subject Areas}

Education Management 


\section{Keywords}

Higher Learning Institutions, HLIs-Industry Linkage, Semi-Industrial Economy

\section{Introduction}

Higher education is no longer a luxury but an essential tool for socio-economic development in every sector. It is indispensable from developed to less developed countries. Higher education plays a pivotal role in excelling socio- economic development through skilled human capital, which is considered to be more important than physical resources. As such, the current economic development strategy of industrialization cannot deny the contribution of Higher Learning Institutions (HLIs) to its success. Universities and other higher learning institutions are the centers of knowledge generation, research activities, and service provision to the community. Furthermore, higher education has become a competitive tool for socio-economic development of all countries regardless of their dissimilarities. Among other roles, HLIs provide the required workforce in various socio-economic sectors [1]. Moreover, studies show that countries that lag in economic development have relatively low utilization of relevant knowledge and skills from academia [2].

\subsection{Education System in Tanzania}

In Tanzania, higher education includes both public and private institutions and is regarded as the highest level of education (See Figure 1). However, the entry qualification can either be a Certificate of Secondary School Education (CSSE) or an Advanced Certificate of Secondary School Education (ACSSE) [3]. That being the case, there are two routes towards higher education, consequently, two regulators. The National Council for Technical Education (NACTE) coordinates all non-university HLIs, whereas; the Tanzania Council for Universities (TCU) regulates, advises and supports all universities in Tanzania [4].

Tanzania is among the top ten fastest-growing economies country in Africa [5]. It has not been behind the move of ensuring that its HLIs are producing highly qualified workforce to contribute to its development [6]. During independence in 1961, Tanzania had only eight qualified medical doctors, two engineers; and no university. After 59 years of independence, the country has created a modest pool of more than 2000 medical doctors, more than 30,000 engineers and more than 50 universities and university colleges [7]. As such, the workforce produced from these HLIs is highly needed for expanded socio-economic development.

As of 2019, there are 70 HLIs both public and private (See Table 1). These universities are regulated by the Tanzania Commission of Universities (TCU). In addition, there are fifty (50) registered and accredited non-university institutions 


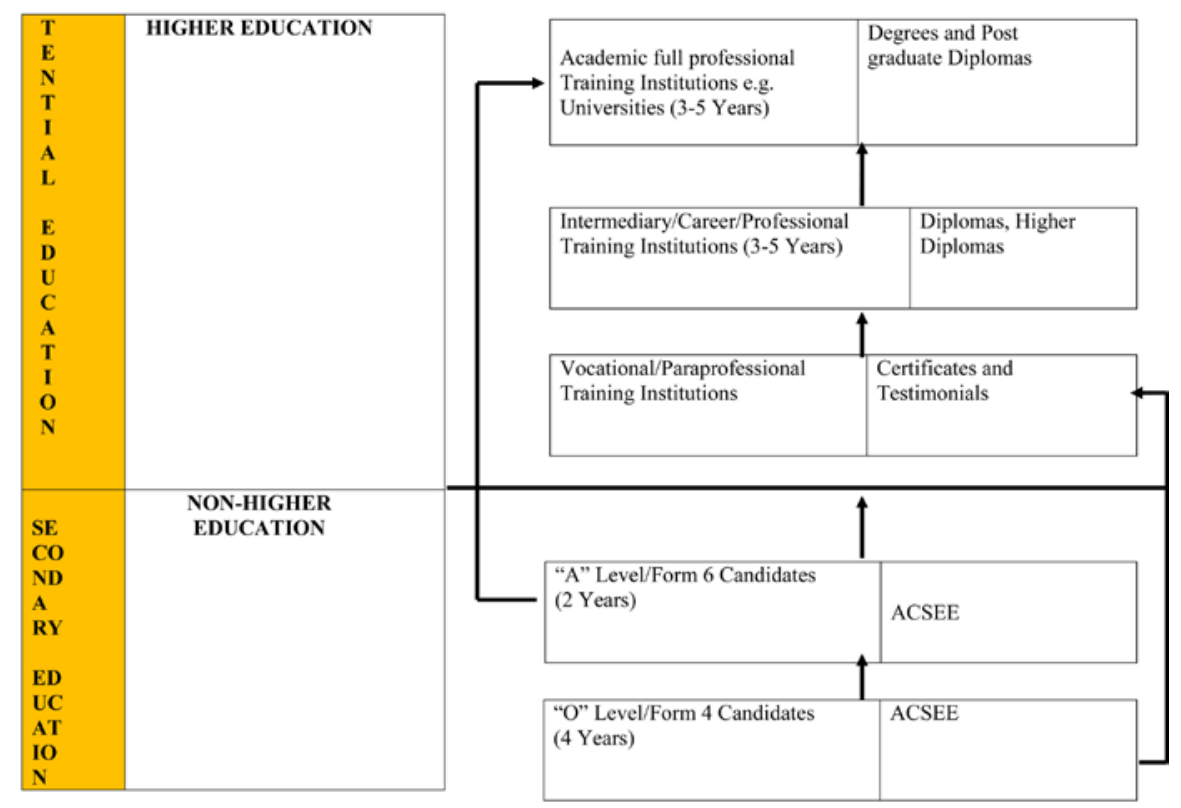

Figure 1. Tanzania education systems from secondary to higher education. Source: (URT, 1999).

Table 1. The number of higher learning institutions in Tanzania under TCU.

\begin{tabular}{ccccc}
\hline Category & University & $\begin{array}{c}\text { University } \\
\text { Colleges }\end{array}$ & $\begin{array}{c}\text { Campuses, Centers and } \\
\text { Institutes }\end{array}$ & $\begin{array}{c}\text { Main } \\
\text { Total }\end{array}$ \\
\hline Public & 12 & 2 & 5 & $\mathbf{1 9}$ \\
Private & 21 & 14 & 16 & $\mathbf{5 1}$ \\
Total & 33 & 16 & 21 & $\mathbf{7 0}$ \\
\hline
\end{tabular}

Source: TCU (2019).

which are under the supervision of the National Council for Technical Education (NACTE). With such increased number of HLIs, a strong link between them and the industry is required to ensure sustainability of both by having a constant exchange of information to meet the industry expectations [8] [9].

Currently, Tanzania is undertaking an economic policy of industrialization endeavored to attain an intermediary economy by 2025 . The emphasis is on the establishment of light industries and redeveloping the already existed ones. The policy direction points to deepening the private sector-led industrial growth as a way of transforming the economy from its heavy reliance on agriculture. However, the same economic development strategy was executed during the first phase of administration by the first president J. K. Nyerere. Diverse industries were established in each region. Unfortunately, the strategy was stagnated by internal factors which include grand corruptions in public finance and mismanagement of such funds [10] [11]. These reasons were associated with globalization impacts (ibid.). Finally, the existed command economy was unable to compete in the global market, and donors suspended their support. Therefore, the current government has to take precautions of various hurdles that may impede 
the success of the current policy.

\subsection{Industrialized Economy in Tanzania}

The industrialized economy in Tanzania has evolved through various stages since independence in 1961; from state-led import substitution, and consequently to deindustrialization under structural adjustment programmes and policy reforms [12]. However, the current industrial agenda has resumed industrial development to be one of her policies. During the first and second phases, the government established various technical training institutions and research centers for manpower production. This enhanced the link between education institutions and the industry. Graduates from technical institutions were deployed in various industries.

Similarly, research centers, particularly for agriculture such as crop and livestock production, were used to produce a variety of seeds and animal breeds, respectively [7]. New crop varieties were produced to cope with the weather changes and to increase production to feed the existed small and medium scale industries. Indeed, the strategy showed positive results at the beginning, and slowly the link declined after the introduction of the free-market economy in the early 1990s. It is envisaged that as the number of HLIs increased their linkage to industries would also expand through knowledge diffusion, innovation and technological development.

However, the increase in graduates, as a consequence of increased HLIs, mismatch with the available employment opportunities. As a result of such unemployment, graduates engage with alternative unprofessional activities, like petty businesses, for survival [1]. This is a significant misuse of resource since the larger part of higher education is government-financed (See Table 1).

Based on the historical background, Tanzania is aware of the role and contribution of the HLIs in economic development, including the current industrialized economic strategy. The qualified workforce, innovation and execution of technology in industries are expected to emanate from HLIs; hence, calling for a strong collaboration.

The 1999 National Higher Education Policy (NHEP) for Tanzania is silent on the HEI-Industry linkage. Nonetheless, there is strong evidence that collaboration between HLIs and industries is inevitable [13]. Industries need an educated and skilled workforce trained by HLI whose focus is in line with social and economic demand [14]. However, this is one of the weaknesses perceived by HLIs, that HLIs-Industry link is not mandatory [15].

\subsection{Statement of the Problem}

There are three general core objectives for most of the HLIs: training, research and consultancy services. These three objectives are interrelated, and they are expected to be balanced in their implementation. For instance, HLIs need to conduct research frequently to cope and accommodate the changes that occur in 
the industry. Likewise, the knowledge accumulated through research and training is disseminated in various industrial sectors for innovation and real problem solving. Thus, demand raised by organizations seeking consultation from HLIs is feedback on how the learning institutions are performing. Nonetheless, studies show that there is an imbalance among the three objectives in HLIs [16].

Additionally, employers are complaining about the incompetence of graduates from HLIs [17]. It is revealed that the mismatch between HLI outputs and labour market demands contribute to such a situation. Therefore, we are skeptical about the existing HLIs-Industry linkage in Tanzania, which might be one of the contributing factors to graduates' rejection by employers. It is also envisaged that the current strategy of industrialization in Tanzania is questionable, if collaboration between HLIs and industries is not effective and efficient [18]. The main objective of this study, therefore, is to assess the extent of the existing linkage between HLIs and industries towards industrialized economy; given its importance in terms of manpower production, innovation and execution of science and technology. To respond to this objective, the study has three specific objectives: first, to assess the interaction between HLIs-Industry through training of workforce; second, to determine the collaboration between HLIs-Industry through research activities, and third, to examine the interaction between HLIs-Industry through consultancy services.

\subsection{Significance of the Study}

The linkage between HLIs and industries benefits the economic development through innovation and technological development. Given the importance of higher education in the industrialization strategy of attaining intermediary economy, the linkage cannot be underestimated. As such, Tanzania needs to strengthen the relationship between these two sectors in terms of training, research and consultancy services. The government has been spending much of its resources, yearly; in HLIs without meeting the expected returns (The government provides loans to both government and private HLI students, pay salaries and other expenses to all HLIs regulators' employees). With the current implementation of industrialization policy, HLIs-Industry linkage is highly required to ensure the quality and sustainability of the strategy. Strong linkage between HLIs and industries reduce unemployment risk [19]. It is therefore, to assess the existing link and recommend accordingly.

\section{Literature Review}

Higher education institutions (HLIs), also known as a tertiary or third level system of education, are generally defined as the post-secondary formal education [20] [21] [22]. HLIs involve universities, colleges, and polytechnic institutions, where the later engage more on practical training than theory. HLIs-Industry linkage refers to collaboration that exists between the two in terms of exchanging knowledge and skills. Likewise, there are mutual benefits between the two. For 
example, industries use knowledge from HLIs, whereas HLIs core activities are not independent of the demand of the industry and community at large. Furthermore, the HLIs-Industry linkage refers to the interaction between any part of the higher education system and industry intending to enhance knowledge and technological transfer. This is a way of building a knowledge stock for organizations sustainability [23].

\subsection{Theoretical Literature}

\subsubsection{Resource Dependence Theory (RDT)}

The Resource Dependence Theory (RDT) suggests that an organization is not self-sufficient in terms of resources and knowledge it needs for its competitiveness and sustainability [24]. As such, an organization has to cooperate with the environment to avoid or manage uncertainty [25]. In light of industry and HLIs collaboration, it plays a vital role in innovation and development. The theory assumes that organizations are components of an extensive system. Furthermore supports that an industry collaborating with universities gains more knowledge than those without such collaboration [26].

\subsubsection{Human-Capacity Theory (HCT)}

Based on Human-capital Theory (HCT), [27] contends that learning a job becomes important in any organization. Consequently, human-capital refers to a set of skills/characteristics acquired by individuals that increase workers' productivity. Indeed, such knowledge and skills are indispensable to the industrial economy. This justifies the linkage between HLIs and the industry where employees work.

\subsubsection{Education Production Function (EPFT)}

Production function connotes, on one hand, the relationship between outputs produced per unit of time, to the number of resources utilized per unit time in producing output [28]. On the other hand, the education production function is the relationship between school and student inputs and a measure of school outputs. The knowledge of education production function is pervasive in setting education institution policy and long-range planning. Therefore, education is equated to production as it can convert inputs into outputs [6].

\subsection{Empirical Studies}

The continuous collaborations between industry and training institutions provide the required knowledge and skills to learners through research and field attachment. The learned skills are necessary for the desired workforce necessary for national development [29]. Further, [17] emphasizes the importance of science and technology in HLIs as the engine of the economy, denying the role of art subjects. Implicitly, this tendency increases the imbalance of the HLIs-Industry linkage and suggests for involving curricula development. Along the same line, [30] argues that the linkage between the academia, government, and the industry, is still very weak. The author further emphasizes that a large 
quantity of academia research is not utilized in real-life environment, except, for the agricultural sector where the government has established its research centers.

The workforce from higher education is registered among the significant factors for the extraordinary growth of the four Asian tigers [31]. It is through a strong collaboration of the academia, the government, and the industry that the goals were achieved. Moreover, the strong ties of historical traditions, Confucianism, religion and other institutions enhanced the process of development. This implies that the effective execution of knowledge and skills from HLIs requires strong collaboration among related stakeholders.

Additionally, the HLIs-Industry linkage stimulates graduates employability in various sectors through internships, joint projects and company involvement in modernizing university curricula [8]. Despite the given importance of the linkage, graduates seem to lack skill in critical thinking, self-management and intercultural skills [32]. As a result, strengthening the linkage might bridge the gap and increase competence to graduates. Generally, HLIs and industry collaboration is said to be a vehicle of innovation and knowledge exchange. The linkage is critically essential [33]. It is also essential for bridging the gap between HLIs and industry.

\subsection{Literature Gap}

The surveyed studies seemed to focus more on university HLIs-Industry link (HIL) while paying less attention to non-university HLIs [23] [25] [29]. However, the number of HLIs in Tanzania, which are non-university, exceeds the number of universities (see Table 1). Additionally, most of these studies are done in developed countries, and tracer studies have been conducted in developing countries, including Tanzania. Poor quality of graduates is more vibrant in developing countries like Tanzania, where linkage shortage might be one of the causes. This motivates the current study to assess the existing linkage between HLIs and industries.

\section{Methodology}

The current study adopted a case study research design in its survey. A qualitative paradigm was also applied in assessing the linkage between HLIs and industries. Furthermore, the data was collected through interviews from purposively selected HLIs and industries interviewees. The data was then analyzed through a thematic method to ascertain the extent of HLIs-industry linkage. The population of this study comprised of universities and non-university, public and private HLIs in Tanzania. A purposive sampling technique was employed to obtain a representative sample based on the objectives of the research objectives.

\subsection{Scope of the Study}

The study selected industries in Dar es Salaam and Coastal Regions in Tanzania. The area was purposively selected due to the availability of a large number of 
industries compared to other regions. Lastly, it was envisaged that the obtained results could be generalized elsewhere in Tanzania on a similar subject.

\subsection{Data Collection Methods}

Relevant data from HLIs and industries were collected through semi-structured interviews and a desk-survey. Five HLIs (universities and non-universities), were purposively selected (See Table 2) based on their long-time experience (age) and categories such that they have built a long relationship with the industry compared to newly established HLIs. This aimed at providing diverse and broad experience of linkages. Ten (10) Faculty Deans (2 from each HLI) and five (5) Research directors (one from each HLI) were interviewed to provide information on existing linkage in the areas of training, research and consultancy services. One representative from the Ministry of Industry and Trade and three more officials were also interviewed. Through a desktop survey, information such as the number of universities and industries information were obtained from their respective databases.

\subsection{Data Analysis}

The data that were obtained through semi-structured interviews are thematically analyzed. Three themes that were used are training, research and consultancy services. These have been drawn from the three core activities of most HLIs. The findings were compared and discussed to provide a sound conclusion. Tables are also used to present some information to have a pictorial representation of the descriptive aspects.

\section{Findings and Discussions}

The obtained data from various sources are categorized into three themes, namely, training, research and consultancy services. The findings and the discussion are also around the mentioned themes.

\subsection{The HLIs-Industry Link through Training Workforce}

An interview with one of the respondents from the Ministry of Industries and

Table 2. Selected HLIs.

\begin{tabular}{cc}
\hline Name of the Institution & Establishment Date \\
\hline University of Dar es Salaam (UDSM) & 1970 \\
Mzumbe University (MU) & 1953 (Local Gov. School) \\
& 1971 (Institute of Development Management) \\
Institute of Finance Management (IFM) & 1972 \\
Tanzania Institute of Accountancy (TIA) & 1973 \\
College of Business Education & 1965 \\
\hline
\end{tabular}

Source: Researcher, 2020. 
Trade revealed that there is a weak link between the industry and the academia. The respondents claimed that:

“...it is far better to employ an engineer from technical college institution than an engineer from universities who are not able to perform. We have experienced this during field practical and when we work with recent employed graduates. We are also not informed if universities research industries to transfer the acquired academia"

Based on such perception and experiences, it is learnt that there is a link between learners' competences and their performance at work place. Learners from universities use a knowledge based curriculum while training institutions executed competence based curriculum. Field practical placement is one of the areas of collaboration between HLIs and industries. Through field practical learners execute their knowledge and skills, which have been acquired during class sessions, in real work life. While some institutions have gained reputation from such collaborations, others have been rejected to place their students in some companies due to poor performance. This implies that the linkage is still not strong between HLIs and industries.

Table 3 shows how the selected industries interact with HLIs. Though industries employ both local and international graduates in various sectors, the Tanzania Cigarette Company (TCC) showed that top management positions are reserved for foreigners. Moreover, most of these industries are privately owned. As such, they are highly dependent on their mother companies for the workforce, research and consultancies. They rarely consult the local HLIs attributing the reasons to cost reduction and trust worth. Such tendencies discourage graduates who are not promoted to take higher positions to execute their knowledge and skills. Similarly, HLIs may not continue producing people are employable hence affecting the progress of different programmes. Moreover, the tendency of industries not using local HLIs for consultancy and research stagnate their capacity in this areas. Thus, the capacity of HLIs in consultancy and research declines. Focusing on bias in employment and consultancy one respondent commended that:

Table 3. Selected and surveyed industries indicating sources of manpower, research and consultancy services.

\begin{tabular}{cccc}
\hline Industry & Manpower Source & $\begin{array}{c}\text { Research } \\
\text { Experts }\end{array}$ & $\begin{array}{c}\text { Consultancy } \\
\text { Services }\end{array}$ \\
\hline $\begin{array}{c}\text { Tanzania Cigarette } \\
\text { Company (TCC) }\end{array}$ & $\begin{array}{c}\text { Local and International } \\
\text { Top Management foreigners }\end{array}$ & $\begin{array}{c}\text { Mother } \\
\text { company }\end{array}$ & $\begin{array}{c}\text { Mother company } \\
\text { and Foreign Firms }\end{array}$ \\
$\begin{array}{c}\text { Dragon Roofing Sheets } \\
\text { Company }\end{array}$ & Local and International & $\begin{array}{c}\text { Mother } \\
\text { company }\end{array}$ & Mother company \\
$\begin{array}{c}\text { SINOMA International } \\
\text { Engineering Company }\end{array}$ & Local and International & $\begin{array}{c}\text { Mother } \\
\text { company }\end{array}$ & Mother company \\
\hline
\end{tabular}

Source: Researcher, 2019. 
“...it does not mean that we do not have competent people to take the top management positions, but local man powers are not trustful. Recently, some local officers at middle management levels have been fired after engaging in fraud activities. It is true that sometimes we lose trust due to unprofessional practices".

The statement justifies that lack of trust will continue spoiling relationship between local workforce and industry owners, particularly foreigners. Similar findings are revealed by [34] in the study of university-industry linkage evolution framework. HLIs must include and emphasize on ethical practices to graduates to harmonize linkages. However, industries moderately accept field practical placement since it is mandatory and provide some employment opportunities for graduates. However, the government remains the principal employer of trained graduates. As such, mostly created knowledge from HLIs is not absorbed by industries to solve problems and increase innovations. If this trend continuous, HLIs will be producing street graduates.

Furthermore, data from the interviews show that there are more linkage similarities than differences among HLIs. Both universities and non-universities are well aware of their linkage status in the three areas of core activities. The long experience on consultancy activity of some universities, particularly in local and central government, gave them an advantage. They also admitted that the linkage between universities and industry is less in research and consultancy. Since HLIs prioritize training at the expense of research and consultancies, knowledge, skills and innovations are transferred to the industry through employment and field works. Indeed, more has to be done in the two core functions to contribute to the ongoing industrialization in the country. Additionally, meager budgets for research and consultancy, mistrust of the industry to universities and lack of awareness are said to be among the significant reasons for the weak linkage decline.

There were similar arguments from non-university institutions. The information was obtained from the heads of research and consultancy when requested to provide experience on HLIs-Industry linkages. Research and consultancy are given less priority as compared to training. For decades, the institutes have been collaborating with local government in research and consultancy and not with the industries. As most industries are privately owned, they are not obliged to collaborate with local HLIs in research and consultancies. As such, some industries are linked to independent experts who enter into informal contacts whenever there is a need to do so. Others engage in the field practical to the industry where the institute receives feedback on their performances. In contrast, industries have negatively commented on the failure of the graduates to meet their expectations. Generally, HLIs-Industry linkage is below the level required regardless of the rapid expansion of both parties.

Lastly, the same as universities, some of the institutes have a reputation in the market in terms of workforce productivity in certain specialized areas of professionalism. Their strength is based on the brand that has been in the market for 
more than four decades. Nevertheless, the quality of its graduates has been declining from time to time, like any other HLIs [35] [36].

\subsection{The HLIs-Industrial Link through Research}

Based on interviews conducted at selected HILs it was revealed that research activities are more subjective as they do not focus on problem-solving. It was further argued that researchers lack skills and meager budget allocated for research activities slow down the linkage [37]. The government collaboration with some HLIs, since their establishment, has built a long-term trust than with the newly established institutions. It was informed that the Mzumbe University and the Tanzania Institute of Accountancy are highly trusted in carrying out government research and consultancy services. Implicitly, other HLIs have been denied a chance to do so.

\subsection{The HLIs-Industry Link through Consultancy Services}

Except for a few government-owned industries, private industries hire experts from private firms for consultations whenever the need arises, and they are not continually doing to reduce costs. Moreover, foreign industries are also linked to other consultant companies abroad, and not the local HLIs. It was also learnt that foreign investors in the industrial sector have low trust in local HLIs (respondents from the industries). As such, they engage consultancies from their original countries. Moreover, there is less motivation for academicians to engage in consultancies due to less or lack of incentives provided by HLIs. Alternatively, they do it privately and informally. It is imperative to HLIs therefore, to introduce attractive incentives schemes for research and consultancy.

\subsection{The Way Forward in HLIs-Industry Linkage}

Generally, much is to be done in improving the linkage for the current policy of industrialization to prevail. The model presented in Figure 2 outlines the

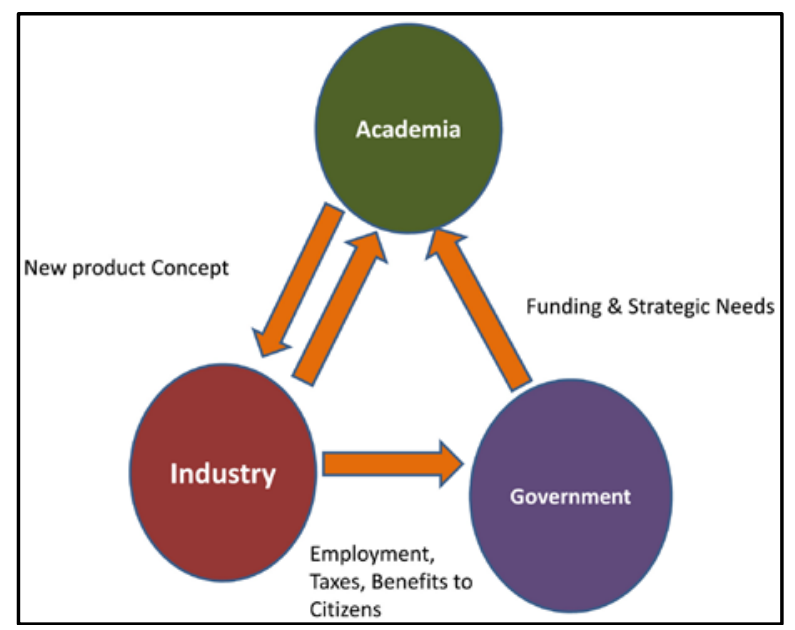

Figure 2. Suggested linkage model.

Source: Adapted from Ankrah and AL-Tabbaa (2016). 
suggested linkage. The Academia (HLIs) invents new product concepts which are put into practice in industries. However, the government plays a middle role of funding and providing strategic support to academia. On the other hand the industry supports the government through provision of employment, paying taxes hence benefits to all citizens.

Activities involved in HLIs-Industry linkage include meetings and networking, communication, training personnel mobility and employment. Each of the activities includes sub-activities that cement the linkage. To make it more useful and effective, the third aspect of government has been added to the model. Table 4 provides more details on HLI-Industry linkage activities.

Thus, HLIs need to be aware of various aspects of linkages to the industries and make it sustainable.

\section{Conclusions}

This study set out to assess the existing linkage between HLIs and the industry in Tanzania, and its influence in current industrial policy. Findings suggest that there exists a weak linkage between HLIs and industry in three aspects namely; training, research and consultancy services. However, training linkage in terms of employment of graduates shows a fair linkage between HLIs and industry compared to research and consultancy. Our findings are like those of other countries in Sub-Saharan Africa [30] [38]. Despite the weak linkage, it is still admitted that knowledge transfer is vital for industrial development and economic vision. In this regard, the current policy of industrialization is likely not to succeed without strengthening HLIs-industry linkage. Higher Education Policy review to legitimize the collaboration can ensure a continuous linkage, hence, make the policy workable.

On the other hand, low motivation, financial constraints, lack of trust among industries to HLIs, cost reduction strategy and incompetence of HLIs in research and consultancy services hampers the linkage. Thus, both internal and external

Table 4. HLI-industry linkage activities.

\begin{tabular}{|c|c|}
\hline Main activity & Sub-activities \\
\hline $\begin{array}{l}\text { Meetings and } \\
\text { networking }\end{array}$ & Conferences, get together, Exhibitions, Trade fair, workshops, forums \\
\hline Communication & $\begin{array}{l}\text { Emails, mails, conference calls, graduation invitations, Co-publication, } \\
\text { Research papers, Newsletters, Reports, Books, Pamphlets }\end{array}$ \\
\hline Training & $\begin{array}{l}\text { Training for industrial personnel, Student placement in industries, } \\
\text { Joint student supervision, Industry involvement in Curriculum } \\
\text { Development, internship }\end{array}$ \\
\hline Personnel mobility & $\begin{array}{l}\text { Lectures by industry members to HLIs and vice versa, Exchange of } \\
\text { personnel }\end{array}$ \\
\hline Employment & $\begin{array}{l}\text { Employment of HLIs Researchers in the industry, employment } \\
\text { of graduates, Representation of Industry Board or HLIs. }\end{array}$ \\
\hline
\end{tabular}

Source: Researcher, 2019. 
assessment of HLIs is needed to improve the quality of their goods and services. HLIs need to change their paradigm from knowledge-based to competence-based while meeting the employers' expectations. Notably, the government is supposed to be part of the collaboration and harmonize the process. The role of the government is to harmonize the linkage through formulation of flexible education policies that influence match between HLIs and industries. It has to provide a conducive environment for investment in industries that will provide an opportunity for HLIs to place learners for practical purposes (internship). Furthermore, the government needs to increase its budget for research development, staff training, HLIs inspections, innovation and invention in HLIs to build competencies of graduates who are needed in industries. This will strengthen the linkages by HLIs meeting the industry expectations.

\section{Conflicts of Interest}

The author declares no conflicts of interest regarding the publication of this paper.

\section{References}

[1] Msami, J. and Wangwe, S. (2016) Manufacturing Transformation: Comparative Studies of Industrial Development in Africa and Emerging Asia. Oxford Scholarship Online. https://doi.org/10.1093/acprof:oso/9780198776987.003.0008

[2] Adeoti, J.O. (2016) University-Industry Linkage and the Challenge of Creating a Developmental University in Nigeria. Towards Quality in African Higher Education, 16, 375-387.

[3] United Republic of Tanzania (2010) Ministry of Education and Vocational Training: Relevance of Technical and Vocational Education and Training (TVET) to Market Demands. United Republic of Tanzania.

[4] United Republic of Tanzania (2016) Tanzania Agricultural Research Institute Act, 2016. Gazette of the United Republic of Tanzania.

[5] World Health Organization (2020) Tanzania to Register Fastest Economic Growth in East Africa. https://www.usaid.gov/tanzania/economic-growth-and-trade

[6] African Review of Business and Technology (2020) Tanzania among top 10 Fastest-Growing Economies.

https://www.africanreview.com/finance/economy/tanzania-among-top-10-fastest-g rowing-economies

[7] Tanzania (1999) National Higher Education Policy, Ministry of Science, Technology and Higher Education, Dar es Salaam. Ministry of Education and Science and Technology.

[8] Ishengoma, E. and Vaaland, T.I. (2016) Can University-Industry Linkages Stimulate Student Employability? Education and Training, 58, 18-44.

https://doi.org/10.1108/ET-11-2014-0137

[9] Ndyali, L. (2016) Higher Education System and Jobless Graduates in Tanzania. Journal of Education and Practice, 7, 116-121.

[10] Tanzania Commission of Universities (2019) Accreditation and Quality Assurance-Recognized Universities. Tanzania Commission of Universities, Dar es Salaam. 
[11] United Republic of Tanzania (1996) The Report on the Residential Inquiry into Corruption in Tanzania. Vol. I and II, Tanzania Government Printers, Dar es Salaam.

[12] Mpehongwa, G. (2013) Academia-Industry-Government Linkages in Tanzania: Trends, Challenges and Prospects. Global Journal of Education Research, 1, 84-91.

[13] Marshall. G. (1998) Human-Capital Theory. A Dictionary of Sociology.

[14] Bituro, K. (2011) How Competent Are Tanzanian Graduates. The Guardian Newspaper.

[15] Tshabangu, I. and Msafiri, A. (2013) Quality Education in Tanzania: Perceptions on Global Challenges and Local Needs. International Journal of Asian Social Science, 3, 800-813.

[16] Vallanti, G and Mascelluti, E. (2015) The Extraordinary Growth of the Four Asian Tigers. Department of Economics and Finance, Middle Tennessee State. https://tesi.luiss.it/15269/1/176201.pdf

[17] Keat, P., Young, P.K., and Erfle, S. (2014) Managerial Economics: Production Function. 7th Edition, Prentice-Hall, Englewood Cliffs, NJ.

[18] Guimón, J. (2013) Promoting University-Industry Collaboration in Developing Countries: The Innovation Policy Platform. Word Bank, Washington DC.

[19] Plewa, C., Korff, N., Johnson, C.R., Rampersad, G., Baaken, T. and MacPherson, G. (2013) The Evolution of University-Industry Linkages a Framework. Journal of Engineering and Technology Management, 30, 21-44. https://doi.org/10.1016/j.jengtecman.2012.11.005

[20] Gustafsson, J. (2012) Education and Research 2011-2016. Ministry of Education and Culture, Finland.

[21] Hirsch, M. (2006) Legislation and Public Policy. New York 9, 817.

[22] Jones, G.A. (2014) An Introduction to Higher Education in Canada. In: Joshi, K.M. and Paivandi, S., Eds., Higher Education across Nations, Vol. 1, B.R. Publishing, Delhi, 1-38.

[23] Ankrah, S. and AL-Tabbaa, O. (2015) Universities-Industry Collaboration: A Systematic Review. Scandinavian Journal of Management, 31, 387-408. https://doi.org/10.1016/j.scaman.2015.02.003

[24] Aldrich, H.E. and Pfeffer, J. (1976) Environments of Organization. Annual Review of Sociology, 2, 79-105. https://doi.org/10.1146/annurev.so.02.080176.000455

[25] Gulbrandsen, M. and Solesvik, M. (2016) University-Industry Linkages in Two Industrial Clusters in Norway. https://doi.org/10.2139/ssrn.2707272

[26] Bol, T., Ciocca Eller, C., van de Werfhorst, H.G. and Di Prete, T.A. (2019) School-to-Work Linkages, Educational Mismatches, and Labor Market Outcomes. American Sociological Review, 84, 275-307. https://doi.org/10.1177/0003122419836081

[27] Makulilo, V.B. (2012) The Proliferation of Private Universities in Tanzania: Quality Compromised? Wudpecker Journal of Educational Research, 1, 51-66.

[28] Coates, D. (1998) Education Production Functions using Instructional Time as an Input. Department of Economics, Public Choice Society, New Orleans. http://dx.doi.org/10.2139/ssrn.98308

[29] Alhassan, M., Aigbavboa, C.O. and Atepor, L. (2016) A Framework for Higher Education and Industry Linkage in the Ghanaian Built Environment. 5th Applied Research Conference in Africa, Cape Coast, 25-27 August 2016, 599-610. 
[30] Mgonja, C. (2017) Enhancing the University-Industry Collaboration in Developing Countries through Best Practices. International Journal of Engineering Trends and Technology, 50, 216-225. https://doi.org/10.14445/22315381/IJETT-V50P235

[31] Ministry of Finance and Planning of Tanzania (2016) National Five-Year Development Plan 2016/17-2020/21: Nurturing Industrialisation for Economic Transformation and Human Development. Ministry of Finance and Planning, Dar es Salaam.

[32] Griffin, M. and Coelhoso, P. (2019) Business Students' Perspectives on Employability Skills Post Internship Experience: Lessons from the UAE. Higher Education, Skills and Work-Based Learning, 9, 60-75.

https://doi.org/10.1108/HESWBL-12-2017-0102

[33] Jamil, F., Ismail, K. and Mahmood, N. (2016) Influence of University-Industry Linkages on the Intellectual Property. Abasyn Journal of Social Sciences, AIC 2016.

[34] Marco Pima, J. (2012) Challenges Facing Higher Education Institutions in Tanzania in Using Portals. The Accountancy and Business Review Journal, 9, 25-35.

[35] Panagiotakopoulos, A. (2012) Employability Skills Development in Greek Higher Education Institutions (HEIs): Implications for Policy Makers. Higher Education, Skills and Work-Based Learning, 2, 141-150. https://doi.org/10.1108/20423891211224621

[36] Trivedi, R. (2016) Does University Play Significant Role in Shaping Entrepreneurial Intention? A Cross-Country Comparative Analysis. Journal of Small Business and Enterprise Development, 23, 790-811. https://doi.org/10.1108/JSBED-10-2015-0149

[37] Bangi, Y. and Sahay, A. (2017) The Influence of Teaching, Research and Consultancy Services on Efficiency Assessment: Experience from Tanzanian Universities. Amity Business Review, 18, 12-27.

[38] Kaijage, E.S. (2010) University-Industry Linkage in Tanzania and Its Impact on SMEs' Development. Business Management Review, 14, 1-26. 